\title{
Bioavailability of vitamin C from mashed potatoes and potato chips after oral administration in healthy Japanese men
}

\author{
Yoshitaka Kondo $^{1 *}$, Chihana Higashi ${ }^{2}$, Mizuki Iwama ${ }^{1}$, Katsuyuki Ishihara ${ }^{2}$, Setsuko Handa ${ }^{1}$, \\ Hiroyuki Mugita $^{2}$, Naoki Maruyama ${ }^{1}$, Hidenori Koga ${ }^{2}$ and Akihito Ishigami ${ }^{1}$ \\ ${ }^{1}$ Aging Regulation, Tokyo Metropolitan Institute of Gerontology, 35-2 Sakae-cho, Itabashi-ku, Tokyo 173-O015, Japan \\ ${ }^{2}$ Research and Development Department, Calbee, Incorporation, 23-6 Kiyohara Kougyoudanchi, Utsunomiya, \\ Tochigi 321-3231, Japan
}

(Received 8 March 2011 - Revised 26 May 2011 - Accepted 5 June 2011 - First published online 15 September 2011)

\section{Abstract}

Potato (Solanum tuberosum) tubers contain vitamin C (VC) and commercial potato chips have more VC content per wet weight by dehydration during frying. However, intestinal absorption of $\mathrm{VC}$ from orally ingested potatoes and its transfer to the blood remains questionable. The present study was designed to determine whether the dietary consumption of potatoes affects VC concentration in plasma and urinary excretion of VC in human subjects. After overnight fasting, five healthy Japanese men between 22 and 27 years of age consumed $87 \mathrm{~g}$ mashed potatoes and $282 \mathrm{~g}$ potato chips. Each portion contained $50 \mathrm{mg}$ of $\mathrm{VC}, 50 \mathrm{mg} \mathrm{VC}$ in mineral water and mineral water. Before and after a single episode of ingestion, blood and urine samples were collected every $30 \mathrm{~min}$ or $1 \mathrm{~h}$ for $8 \mathrm{~h}$. When measured by subtraction of the initial baseline value before administration of potatoes from the values measured throughout the $8 \mathrm{~h}$ test period, plasma VC concentrations increased almost linearly up to $3 \mathrm{~h}$. Subsequently, the values of potato-fed subjects were higher than those of water, but did not differ significantly from those of VC in water $(P=0 \cdot 14$ and $P=0 \cdot 5)$. Less VC tended to be excreted in urine during the $8 \mathrm{~h}$ test than $\mathrm{VC}$ in water alone (17.0 (SEM 7.5) and 25.9 (SEM 8.8) $v .47 .9$ (SEM 17.9) $\mu \mathrm{mol} / \mathrm{mmol}$ creatinine). Upon human consumption, mashed potatoes and potato chips provide VC content that is effectively absorbed in the intestine and transferred to the blood. Clearly, potatoes are a readily available source of dietary VC.

\section{Key words: Bioavailability: Vitamin C: Mashed potatoes: Potato chips}

Potato tubers (Solanum tuberosum) are a staple food in many countries worldwide, because they contain an excellent variety of nutrients such as carbohydrates, protein, lipids, dietary fibre, minerals ( $\mathrm{Zn}, \mathrm{Fe}, \mathrm{Mg}, \mathrm{Ca}, \mathrm{K}$ and $\mathrm{Na}$ ) and vitamins (vitamin $\mathrm{C}(\mathrm{VC})$, vitamin $\mathrm{B}_{1}$, vitamin $\mathrm{B}_{2}$, vitamin $\mathrm{B}_{6}$, niacin, pantothenic acid and folic acid ${ }^{(1,2)}$. Especially notable is the potato's abundant VC content $(35 \mathrm{mg} / 100 \mathrm{~g} \text { wet weight })^{(2)}$. $\mathrm{VC}$ is a potent soluble antioxidant and cofactor for several hydroxylases involved in catecholamine biosynthesis and collagen polymerisation ${ }^{(3)}$. Since the human body cannot synthesise VC, our VC intake most often comes from foods. Historically, the ingestion of potatoes has contributed to the prevention of VC-deficiency disease, that is, scurvy. Recently, VC has been associated with numerous health benefits including decreased risk of $\mathrm{CVD}^{(4)}$, stroke ${ }^{(5-8)}$, age-related cataracts $^{(9,10)}$ and type 2 diabetes mellitus and ${ }^{(11,12)}$ has also decreased the frequency of common colds ${ }^{(13)}$.
Potatoes are usually prepared for eating by baking, boiling, steaming, dehydrating or frying. However, each of these cooking methods causes a lesser or greater loss of $\mathrm{VC}^{(1,14,15)}$. However, we previously found that the VC content per wet weight of commercial potato chips was about twice that of unprocessed raw potatoes ${ }^{(16)}$, because rapid frying and complete dehydration during the frying process minimised VC loss. Similarly, potatoes processed by boiling and mashing retain VC. Thus, mashed potatoes and potato chips seem to be a superior dietary source of $\mathrm{VC}$ to promote human health.

The effect of all dietary compounds depends on the retention of nutrients in blood and tissues. Therefore, actual bioavailability represents a fundamental issue. Orally administered VC is first absorbed in the small intestine, delivered to the liver, and then circulates in the blood followed by uptake into various tissues ${ }^{(17-19)}$. In the kidney, proximal tubules absorb $\mathrm{VC}$ in primitive urine and release it into the plasma. When VC concentration in primitive urine exceeds

Abbreviations: AUC, area under the curve; ECD, electrochemical detector; MPA, metaphosphoric acid; VC, vitamin C.

*Corresponding author: Dr Y. Kondo, fax +8133579 4776, email kondo@tmig.or.jp 
the reabsorption capacity in proximal tubules, excess VC is excreted in urine. The bioavailability of VC ingested in water is well understood in human subjects ${ }^{(20-24)}$. Surprisingly, though, no studies have documented the bioavailability of VC from potatoes prepared by mashing or frying as chips. Therefore, we measured VC concentrations in the plasma and urine of human subjects for $8 \mathrm{~h}$ after orally administering mashed potatoes and potato chips.

\section{Subjects and methods}

\section{Subjects}

A total of five healthy male volunteers aged $22-27$ years (24 (SEM 1) years) were enrolled in the present study. Their mean BMI was $20 \cdot 3(\operatorname{sem} 2 \cdot 8) \mathrm{kg} / \mathrm{m}^{2}$ and did not change significantly during the present study. These subjects took no dietary supplements or medications, did not smoke and were not habitual drinkers of alcoholic beverages. None of the subjects had a chronic illness or food allergy. All study participants were in good health on the basis of a medical history, a physical examination and normal results on clinical laboratory tests, including measurement of total protein (75 (SEM 6) g/l), albumin $(57.5($ SEM 4.8$) \mathrm{g} / \mathrm{l})$, glucose (4.8 (SEM $0 \cdot 2) \mathrm{mmol} / \mathrm{l}$ ), aspartate aminotransferase (15 (SEM 2) U/l), alanine aminotransferase (15 (sem 6) U/1), TAG (0.26 (sem $0 \cdot 12) \mathrm{mmol} / \mathrm{l})$, total cholesterol $(4 \cdot 18(\operatorname{sem~} 0 \cdot 61) \mathrm{mmol} / \mathrm{l})$, urea $\mathrm{N}(1 \cdot 94(\operatorname{sem~} 0 \cdot 31) \mathrm{mmol} / \mathrm{l})$ and creatinine $(72$ (sем 5) $\mu \mathrm{mol} / \mathrm{l})$. The present study was conducted according to the guidelines laid down in the Declaration of Helsinki and all procedures involving human subjects were approved by the Clinical Research Ethics Committee of the Tokyo Metropolitan Institute of Gerontology, Tokyo, Japan. Written informed consent was obtained from all subjects.

\section{Study design}

A cross-over study at 4-week intervals was conducted as illustrated in Fig. 1. Subjects enrolled in the study received a 'standard' daily meal during the $3 \mathrm{~d}$ before the day of $\mathrm{VC}$ testing. The standard menu was as follows: (1) breakfast, consisting of bread, cheese and milk; (2) lunch of a commercial frozen meal (Nichirei Foods Direct, Inc., Tokyo, Japan) and rice (Sato Foods Industries Company Limited, Niigata, Japan); (3) dinner of a commercial frozen meal, rice and miso soup with pork and vegetables (Hanamaruki Foods, Inc., Tokyo, Japan). The standard meal was controlled for the content of VC and other nutrients (Table 1). The amounts of energy, protein, fat, carbohydrates and $\mathrm{VC}$ delivered were calculated by using the values provided by the manufacturers and listed in the Standard Tables of Food Composition in Japan $^{(2)}$. VC concentration in these standard meals, in part, was measured by using HPLC and an electrochemical detector (ECD). For the VC bioavailability study, subjects were fasted $>12 \mathrm{~h}$ after their last meal. Their urine was thoroughly excreted at 08.00 hours, after which the subjects immediately drank $50 \mathrm{ml}$ mineral water (Coca-Cola (Japan) Company, Limited, Tokyo, Japan). Blood and urine samples were then collected at 09.00 hours, followed by the subjects' ingestion of a test sample consisting of $282 \mathrm{~g}$ mashed potatoes including $50 \mathrm{mg} \mathrm{VC}$ and $100 \mathrm{ml}$ mineral water (food group 1), $87 \mathrm{~g}$ potato chips including $50 \mathrm{mg} \mathrm{VC}$ and $100 \mathrm{ml}$ mineral water (food group 2), $50 \mathrm{mg}$ VC (DSM Nutrition Japan K.K., Tokyo, Japan) freshly dissolved in $100 \mathrm{ml}$ mineral water (food group 3) and $100 \mathrm{ml}$ mineral water (food group 4) at 4-week intervals. Their blood was then sampled every $30 \mathrm{~min}$ for up to $4 \mathrm{~h}$ and every $1 \mathrm{~h}$ from 4 to $8 \mathrm{~h}$. Urine was sampled every $1 \mathrm{~h}$ up to $8 \mathrm{~h}$. To provide enough urine samples, the subjects drank $50 \mathrm{ml}$ of mineral water every $1 \mathrm{~h}$ until $8 \mathrm{~h}$ after collection of the final plasma and urine samples.

\section{Collection of blood and urine samples}

For plasma VC analysis, each blood sample was drawn into a VENOJECT $^{\circledR}$ collection tube (Terumo Corporation, Tokyo, Japan) containing EDTA-2K as an anticoagulant. For plasma glucose analysis, each VENOJECT ${ }^{\circledR}$ collection tube contained EDTA-2Na and heparin-Na as an anticoagulant and $\mathrm{NaF}$ as an inhibitor of glucose degradation. For clinical laboratory

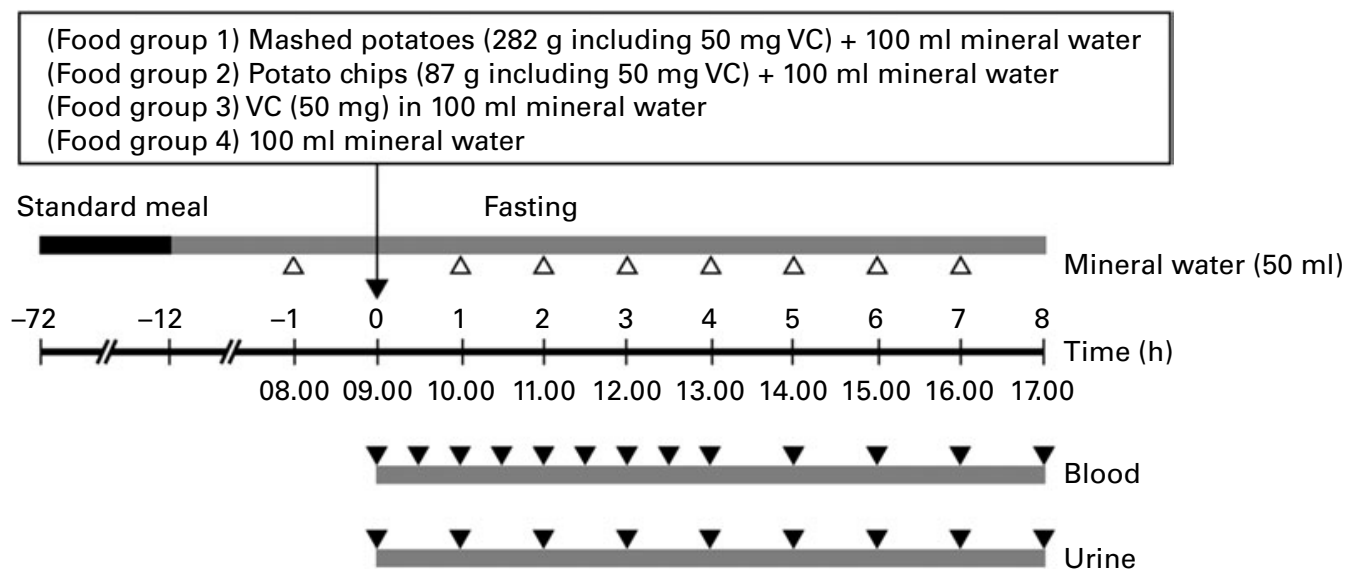

Fig. 1. Scheme of the study in which the same five volunteers were fed at 4-week intervals the following vitamin $\mathrm{C}$ (VC) intake: $282 \mathrm{~g}$ mashed potatoes containing $50 \mathrm{mg}$ VC with $100 \mathrm{ml}$ mineral water (food group 1), $87 \mathrm{~g}$ potato chips containing $50 \mathrm{mg}$ VC with $100 \mathrm{ml}$ mineral water (food group 2), $50 \mathrm{mg}$ VC in $100 \mathrm{ml}$ mineral water (food group 3) and $100 \mathrm{ml}$ mineral water (food group 4). Each food group was orally administered at 08.00 hours on the day of the loading experiment. 
Table 1. Composition of the standard meal

\begin{tabular}{|c|c|c|c|}
\hline & \multicolumn{3}{|c|}{ Before the experiments } \\
\hline & $3 d$ & $2 d$ & $1 d$ \\
\hline Energy (kJ) & 8598 & 8598 & 8473 \\
\hline Protein $(\mathrm{g})$ & 71.1 & $67 \cdot 0$ & 67.4 \\
\hline Fat $(\mathrm{g})$ & $57 \cdot 2$ & $56 \cdot 0$ & 57.9 \\
\hline Carbohydrates $(\mathrm{g})$ & 313.0 & 319.9 & 307.5 \\
\hline Vitamin C (mg) & $36 \cdot 3$ & $16 \cdot 8$ & $13 \cdot 6$ \\
\hline
\end{tabular}

tests of serum, each VENOJECT ${ }^{\circledR}$ collection tube contained procoagulant. Plasma and sera were obtained by centrifugation at $1700 \mathrm{~g}$ for $15 \mathrm{~min}$ at $4^{\circ} \mathrm{C}$. After plasma was collected, $100 \mu \mathrm{l}$ of the supernatant were immediately mixed with $450 \mu$ l of cold $3 \%(\mathrm{w} / \mathrm{v})$ metaphosphoric acid (MPA; Wako Pure Chemical Industries Limited, Osaka, Japan) containing $1 \mathrm{mmol} / \mathrm{l}$ of the metal ion chelator EDTA (Dojindo Laboratories, Kumamoto, Japan) for VC analysis. Urine samples from each subject were first measured to record their volume; then $600 \mu \mathrm{l}$ of urine were immediately mixed with an equal volume of cold $10 \% \mathrm{MPA}$ and $1 \mathrm{mm-EDTA}$ for VC analysis. Remaining aliquots of urine were used for creatinine analysis. All samples were stored at $-80^{\circ} \mathrm{C}$ until use.

\section{Preparation of mashed potatoes and potato chips}

Potato (S. tuberosum cultivar Toyoshiro) tubers of similar size and appearance were obtained for the experiment from a field in Ibaraki, Japan, in July 2009 and stored for a few days. The unpeeled potatoes were washed in tap water and air-dried on filter paper. In preparation for mashing, potatoes were steamed for $50 \mathrm{~min}$ in a steam cooker, peeled, mashed with a potato masher and mixed well with $1 \%(\mathrm{w} / \mathrm{w})$ salt. The steamed samples were stored at $-80^{\circ} \mathrm{C}$ until use. Potato chips were prepared as the commercial product manufactured by CALBEE, Inc., Tochigi, Japan. That is, peeled potatoes were sliced and immersed in tap water, then fried in rice and palm olein mixing oil for a few minutes. After the frying process, to avoid degradation of $\mathrm{VC}$, potato chips were stored in a $\mathrm{N}_{2}$ gas-filled pouch with an $\mathrm{Al}$ vapour-deposited film at room temperature.

\section{Measurement of vitamin C}

VC was measured as the sum of a reduced and oxidised form by using HPLC and ECD as described previously ${ }^{(25)}$. For analysis of plasma VC, $100 \mu \mathrm{l}$ of the subjects' plasma were mixed with $450 \mu \mathrm{l}$ of cold $3 \% \mathrm{MPA}$ and $1 \mathrm{~mm}$-EDTA and centrifuged at $21000 \mathrm{~g}$ for $15 \mathrm{~min}$ at $4^{\circ} \mathrm{C}$. For analysis of VC content in mashed potatoes and potato chips, $0.4 \mathrm{~g}$ of samples were homogenised with 14 volumes of cold 5.4\% MPA and $1 \mathrm{~mm}-$ EDTA by using a high-speed homogeniser (Polytron, Kinematica AG, Lucerne, Switzerland) and centrifuged at $21000 \mathrm{~g}$ for $15 \mathrm{~min}$ at $4^{\circ} \mathrm{C}$. For determination of $\mathrm{VC}$ after the resulting reduction of an oxidised form to a reduced form, $90 \mu \mathrm{l}$ of the supernatant were incubated with $10 \mu \mathrm{l}$ of $350 \mathrm{~mm}$-Tris(2carboxyethyl)phosphine hydrochloride for $2 \mathrm{~h}$ at $4^{\circ} \mathrm{C}$. Then, the samples were diluted with $965 \mu \mathrm{l}$ of cold $5 \%$ MPA and $1 \mathrm{~mm}$-EDTA followed by centrifugation at $21000 \mathrm{~g}$ for $10 \mathrm{~min}$ at $4{ }^{\circ} \mathrm{C}$. A volume of $10 \mu \mathrm{l}$ of that supernatant was injected into a Waters 2695 separation module coupled with a Waters 2465 ECD (Nihon Waters K.K., Tokyo, Japan) and separated by using an Atlantis dC18 $5 \mu \mathrm{m}$ column $(4.6 \times 150 \mathrm{~mm}$; Nihon Waters K.K.) combined with an Atlantis dC18 $5 \mu \mathrm{m}$ guard column $(4.6 \times 20 \mathrm{~mm}$; Nihon Waters K.K.). The mobile phases consisted of $50 \mathrm{~mm}$-phosphate buffer ( $\mathrm{pH} 2 \cdot 8$ ), $0.54 \mathrm{~mm}$-EDTA, and $2 \%$ methanol. The flow rate was $1.3 \mathrm{ml} / \mathrm{min}$, and temperatures for column and ECD were set at $30^{\circ} \mathrm{C}$. Electrical signals were detected by using an ECD with a glassy carbon electrode at $+0 \cdot 6 \mathrm{~V}$. All electrochemical signal data from the ECD were recorded by the Waters Empowere2 software (Nihon Waters K.K.).

\section{Measurement of urinary creatinine}

The concentration of creatinine in urine was determined enzymatically by using a Creatinine Test Wako Kit (Wako Pure Chemical Industries, Limited, Osaka, Japan) according to the manufacturer's instructions ${ }^{(26)}$.

\section{Statistical analysis}

The values are expressed as mean values with their standard errors. The $8 \mathrm{~h}$ area under the curve (AUC) of increased plasma VC concentration was calculated using the trapezoidal rule as a summary measure of VC bioavailability. Statistical analyses were performed with KareidaGraph software (Synergy Software, Reading, PA, USA). The significance of differences among the treatment groups and at different time points was determined by repeated-measures ANOVA. Differences between means were further evaluated by the Tukey's honestly significant difference test. Differences were considered significant at $P<0 \cdot 05$.

\section{Results}

When we compared the two preparations of potatoes, the VC content was 2.24-fold higher in potato chips (57.2 (SEM $0.4) \mathrm{mg}$ ) than in mashed potatoes $(17.7$ (SEM 0.1) $\mathrm{mg}) / 100 \mathrm{~g}$ weight. The water content of potato chips (1.9 (SEM 0.1) g/ $100 \mathrm{~g}$ ) was marginally $2.5 \%$ of the value of mashed potatoes (76.7 (sem 0.02) g/100 g).

To clarify whether VC from mashed potatoes and potato chips is absorbed in the intestine and transferred to the blood after oral consumption, we serially measured the $\mathrm{VC}$ concentrations of the subjects' plasma after consumption of $282 \mathrm{~g}$ mashed potatoes and $87 \mathrm{~g}$ potato chips, both of which contained $50 \mathrm{mg}$ of $\mathrm{VC}$. Subsequently, each subject also received $50 \mathrm{mg} \mathrm{VC}$ in water and water as controls. The four groups of food were administered at 4-week intervals. At the initial measurement of baseline plasma VC concentrations among the recipients of each food group, no significant differences $(P=0.3)$ were found for mashed potatoes $(34.0$ (SEM $4 \cdot 2) \mu \mathrm{mol} / \mathrm{l})$, potato chips $(40 \cdot 2$ (sEm 3.1) $\mu \mathrm{mol} / \mathrm{l}), \mathrm{VC}$ in water (41.5 (SEM 2.0) $\mu \mathrm{mol} / \mathrm{l})$ and water (37.2 (sem 2.1) $\mu \mathrm{mol} / \mathrm{l})$. To compare the later changes after oral 


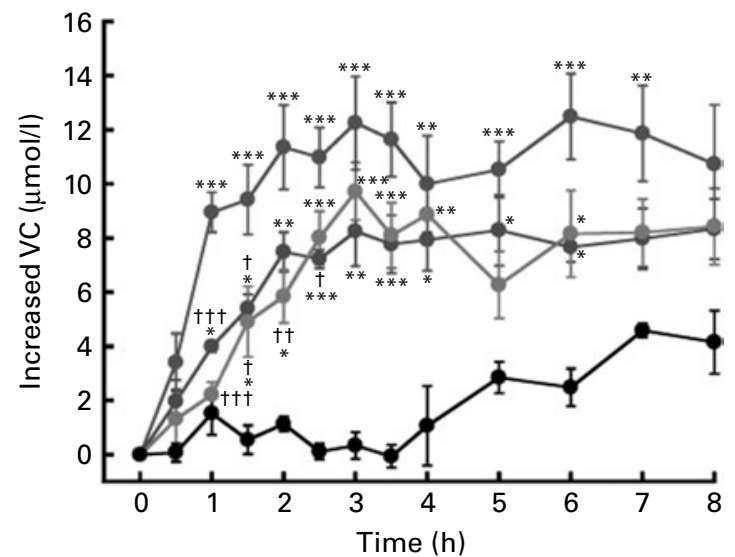

Fig. 2. Increased plasma vitamin C (VC) concentration after consumption of mashed potatoes $(\bullet)$, potato chips $(\bullet)$, VC in water $(\bullet)$ and water $(\bullet)$. Values are means, with their standard errors represented by vertical bars (n 5). Values reached statistical significance for group $(P<0.001)$, time $(P<0.0001)$ and food group $\times$ time interaction $(P<0.0001)$ by repeatedmeasures ANOVA. Mean values were significantly different from water: ${ }^{\star} P<0.05,{ }^{* \star} P<0.01$ and ${ }^{* *} P<0.001$ (ANOVA and Tukey's honestly significance test). Mean values were significantly different from VC in water: $\dagger P<0.05$, $† \dagger P<0.01$, $\dagger \dagger \dagger P<0.001$ (ANOVA and Tukey's honestly significance test). For mashed potatoes, values at 2, 2.5, 3, 3.5, 4, 5, 6, 7 and $8 \mathrm{~h}$ were significantly higher than values at $0,0.5$ and $1 \mathrm{~h}(P<0.05)$; values at $1.5 \mathrm{~h}$ were significantly higher than values at 0 and $0.5 \mathrm{~h}(P<0.05)$; values at $1 \mathrm{~h}$ were significantly higher than values at $0 \mathrm{~h}(P<0.05)$ (repeated-measures ANOVA and Tukey's honestly significance test). For potato chips, values at $3 \mathrm{~h}$ were significantly higher than values at $0,0.5,1,1.5,2$ and $5 \mathrm{~h}(P<0.05)$; values at 4 and $8 \mathrm{~h}$ were significantly higher than values at $0,0.5,1$ and $1.5 \mathrm{~h}$ $(P<0.05)$; values at $2,2.5,3.5,5,6$ and $7 \mathrm{~h}$ were significantly higher than values at $0,0.5$ and $1 \mathrm{~h}(P<0.05)$; values at $1.5 \mathrm{~h}$ were significantly higher than values at 0 and $0.5 \mathrm{~h}(P<0.05)$ (repeated-measures ANOVA and Tukey's honestly significance test). For VC in water, values at 1, 1.5, 2, 2.5, $3,3.5,4,5,6,7$ and $8 \mathrm{~h}$ were significantly higher than values at 0 and $0.5 \mathrm{~h}$ $(P<0.01)$ (repeated-measures ANOVA and Tukey's honestly significance test). For water, values at $5 \mathrm{~h}$ were significantly higher than values at $3.5 \mathrm{~h}$ $(P<0.05)$; values at $7 \mathrm{~h}$ were significantly higher than values at $0,0.5,1,1.5$, $2,2.5,3,3.5$ and $4 \mathrm{~h}(P<0.05)$; values at $8 \mathrm{~h}$ were significantly higher than values at $0,0.5,1.5,2,2.5,3,3.5$ and $4 \mathrm{~h}(P<0.05)$ (repeated-measures ANOVA and Tukey's honestly significance test).

consumption of mashed potatoes, potato chips, VC in water and water, we calculated the time course of increased plasma VC concentrations by subtracting the initial baseline values from the total at each subsequent blood/urine sampling (Fig. 2). In plasma, VC concentrations from mashed potatoes and potato chips almost linearly increased at first in a timedependent manner after oral consumption and then reached maximal levels at $3 \mathrm{~h}$. At the $3 \mathrm{~h}$ mark, the increase in plasma VC concentrations from mashed potatoes was 8.3 (SEM 1.3 ) $\mu \mathrm{mol} / \mathrm{l}$ and from potato chips was 9.7 (SEM $1 \cdot 1) \mu \mathrm{mol} / \mathrm{l}$. These increases were higher than those of water ( 0.3 (sEm 0.5$) \mu \mathrm{mol} / 1 ; P=0.002$ and $P=0.0003$, respectively), but not significantly different from each other $(P=0.8)$ or from that of $\mathrm{VC}$ in water $(12.3(\operatorname{sem} 1.7) \mu \mathrm{mol} / \mathrm{l})$. In fact, the only significant change in plasma VC concentration was a decrease for potato chips at $5 \mathrm{~h}$ after ingestion. These increases of $\mathrm{VC}$ in plasma for mashed potatoes were higher than those for water at $1 \mathrm{~h} \quad(P=0.046), 1.5 \mathrm{~h} \quad(P=0.02)$, $2 \mathrm{~h} \quad(P=0.002), \quad 2.5 \mathrm{~h} \quad(P<0.0001), 3 \mathrm{~h} \quad(P=0.002), 3.5 \mathrm{~h}$ $(P=0.0005), 4 \mathrm{~h}(P=0.02), 5 \mathrm{~h}(P=0.012)$ and $6 \mathrm{~h}(P=0 \cdot 04)$; for potato chips, they were higher than those for water at $1.5 \mathrm{~h} \quad(P=0.03), 2 \mathrm{~h} \quad(P=0.02), 2.5 \mathrm{~h} \quad(P<0.0001), 3 \mathrm{~h}$ $(P=0.0003), \quad 3.5 \mathrm{~h} \quad(P=0.0003), \quad 4 \mathrm{~h} \quad(P=0.006)$ and $6 \mathrm{~h}$ $(P=0.02)$. On the other hand, these increases of $\mathrm{VC}$ in plasma for mashed potatoes were lower than those of $\mathrm{VC}$ in water at $1 \mathrm{~h}(P=0.0001), 1.5 \mathrm{~h}(P=0.048)$ and $2.5 \mathrm{~h}(P=0.02)$; for potato chips, they were lower than those of $\mathrm{VC}$ in water at $1 \mathrm{~h}(P<0.0001), 1.5 \mathrm{~h}(P=0.02)$ and $2 \mathrm{~h}(P=0.006)$. Overall, at different time points, the values between mashed potatoes and potato chips were not significantly different $(P>0.05)$. Additionally, VC concentrations in plasma of all four food groups did not return to baseline until $8 \mathrm{~h}$ after consumption.

Next, we calculated the AUC for increased plasma VC concentration at $8 \mathrm{~h}$ after administration to estimate the bioavailability of VC in mashed potatoes and potato chips (Fig. 3). The AUC for mashed potatoes (55.1 (SEm 5.7) $\mu \mathrm{mol} \times \mathrm{h} / \mathrm{l})$ and potato chips $(53.6(\operatorname{SEM} 8 \cdot 1) \mu \mathrm{mol} \times \mathrm{h} / \mathrm{l})$ were higher than that of water $(14.6(\operatorname{sem} 3.3) \mu \mathrm{mol} \times \mathrm{h} / \mathrm{l} ; P=0.004$ and $P=0.0048$, respectively). On the other hand, these values tended to be $32 \%$ less and were $34 \%$ less than that of $\mathrm{VC}$ in water $(81.5$ (SEM 8.9) $\mu \mathrm{mol} \times \mathrm{h} / \mathrm{l} ; \quad P=0.06$ and $P=0.048$, respectively). There was no significant difference between the AUC for mashed potatoes and potato chips $(P=0 \cdot 99)$.

Urinary excretion of $\mathrm{VC}$ after consumption of mashed potatoes, potato chips, VC in water and water was similarly measured to reveal their differing effect, if any. Total spontaneous urine volumes over $8 \mathrm{~h}$ after intake of mashed potatoes, potato chips, VC in water and water were 321 (SEM 15), 331 (SEM 47), 326 (SEM 73) and 286 (SEM 15) ml, respectively, and not significantly different $(P=0 \cdot 9)$. Similarly, the total urine creatinine over that $8 \mathrm{~h}$ time span did not significantly differ among mashed potatoes, potato chips, VC in water and water (5.30 (SEM 0.23), $5 \cdot 48$ (SEM 0.24), $5 \cdot 42$ (SEM $0 \cdot 29)$ and $4.81(\operatorname{sem} 0.34) \mathrm{mmol}$, respectively, $P=0 \cdot 3)$. However, VC in water was excreted at a significantly elevated rate at 3 and $4 \mathrm{~h}$ after intake (Fig. 4(a)). Urinary excretion of

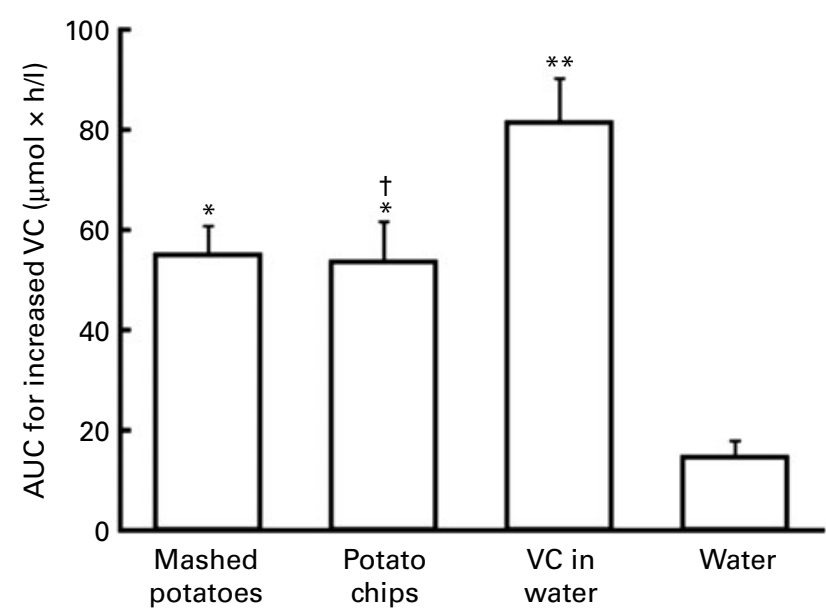

Fig. 3. Area under the curve (AUC) for increased plasma vitamin $C$ (VC) concentration until $8 \mathrm{~h}$ after consumption of mashed potatoes, potato chips, VC in water and water. Values are means, with their standard errors represented by vertical bars $(n 5)$. Mean values were significantly different from those of water: ${ }^{\star} P<0.005$ and ${ }^{* \star} P<0.0001$. † Mean value was significantly different from that of VC in water: $P<0.05$. 
(a)

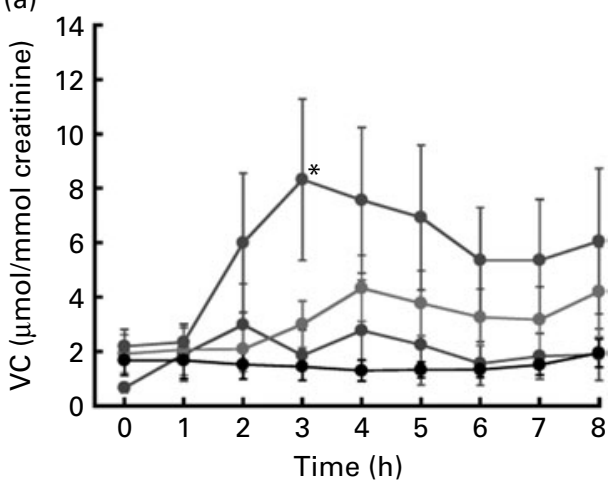

(b)

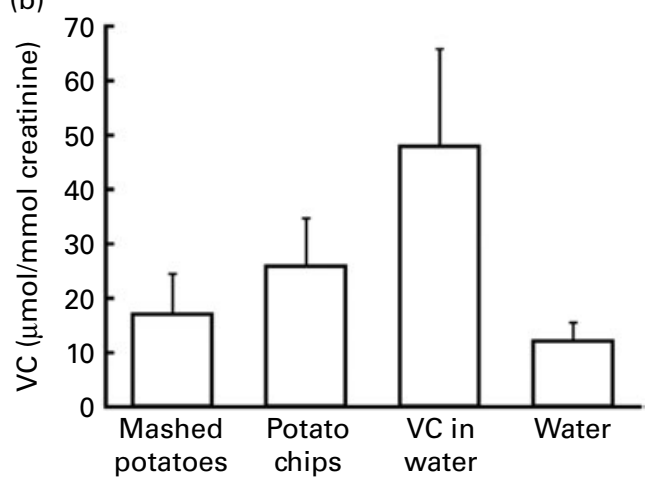

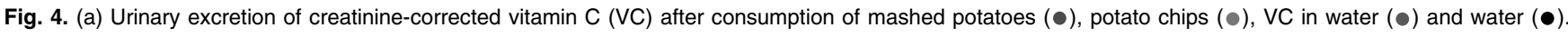
Values are means, with their standard errors represented by vertical bars $(n 5)$. There was no significant main effect of food group $(P=0 \cdot 14)$; however, the main effect of time reached significance $(P<0.0001)$ as did the food group $\times$ time interaction $(P=0.0012)$ by repeated-measures ANOVA. ${ }^{*}$ Mean values were significantly different from water $(P<0.05$; ANOVA and Tukey's honestly significance test). For mashed potatoes and water, values at different time points did not show a significant difference $(P=0.7$ and $P=0.14$, respectively, repeated-measures ANOVA). For potato chips, values at 4 and $8 \mathrm{~h}$ were significantly higher than values at 0,1 and $2 \mathrm{~h}(P<0.05)$; values at $5 \mathrm{~h}$ were significantly higher than values at $0 \mathrm{~h}(P<0.05)$ (repeated-measures ANOVA and Tukey's honestly significance test). For VC in water, values at 3 and $4 \mathrm{~h}$ were significantly higher than values at 0 and $1 \mathrm{~h}(P<0.05)$ (repeated-measures ANOVA and Tukey's honestly significance test). For water, values at different time points did not show a significant difference $(P=0.14$, repeated-measures ANOVA). (b) Urinary excretion of creatininecorrected VC until $8 \mathrm{~h}$ after consumption of mashed potatoes, potato chips, VC in water and water. Mean values were not significantly different among all groups $(P=0 \cdot 13 ;$ ANOVA).

VC from potato chips was slightly elevated at 4,5 and $8 \mathrm{~h}$, but not to a significantly different extent from that of $\mathrm{VC}$ in mashed potatoes and water until $8 \mathrm{~h}$. Compared with VC in water, urinary excretion of $\mathrm{VC}$ at $3 \mathrm{~h}$ was 78 and $64 \%$ less than that from mashed potatoes (1.9 (SEM 0.9) $\mu \mathrm{mol} / \mathrm{mmol}$ creatinine) and from potato chips (3.0 (sem 0.9$) \mu \mathrm{mol} / \mathrm{mmol}$ creatinine) but was not a significant factor $(P=0.056$ and $P=0 \cdot 14$ ), respectively. Total amounts of urinary VC excreted at $8 \mathrm{~h}$ were 64 and $46 \%$ less than that from mashed potatoes (17.0 (SEM 7.5) $\mu \mathrm{mol} / \mathrm{mmol}$ creatinine, 1.7 (SEM 0.7) $\mathrm{mg} \mathrm{VC}$ ) or potato chips $(25.9$ (SEM 8.8$) \mu \mathrm{mol} / \mathrm{mmol}$ creatinine, 2.9 (SEM 1.1) mg VC) compared with VC in water (47.9 (SEM 17.9) $\mu \mathrm{mol} / \mathrm{mmol}$ creatinine, 5.4 (SEM $2 \cdot 2$ ) $\mathrm{mg} \mathrm{VC}$ ), but again, the difference was not statistically significant $(P=0.2$ and $P=0.5$; Fig. $4(\mathrm{~b}))$.

\section{Discussion}

In the present study, we show for the first time that the dietary intake of mashed potatoes and potato chips in amounts that contained $50 \mathrm{mg}$ of VC was equally effective at increasing plasma VC concentrations, i.e. both yielded an increase of $24 \%$. This outcome indicates that (1) VC from ingested potatoes is well absorbed in the intestine and transferred to the blood and (2) processing such as steaming/mashing or frying does not affect the bioavailability of $\mathrm{VC}$ in potatoes. Furthermore, after the consumption of mashed potatoes or potato chips, the increased $\mathrm{VC}$ concentration in plasma up to the maximal level and for $8 \mathrm{~h}$ remained greater, and the urinary excretion of creatinine-corrected VC was relatively lower than both values after the intake of VC in water. Overall, the bioavailability of $\mathrm{VC}$ from potatoes, either mashed or fried, exceeded that from VC in water.

Human subjects do not usually eat raw potatoes but, instead, consume them in home-processed and commercial preparations. Han et al. ${ }^{(14)}$ reported that potatoes homeprocessed by boiling, pressure-cooking, frying, sautéing, braising, baking or microwaving lose VC to varying degrees. In that study, the $\mathrm{VC}$ content of mashed potatoes (17.7 (SEM $0 \cdot 1) \mathrm{mg} / 100 \mathrm{~g}$ ) was at a lower level presumably because the combined processes of steaming, mashing and additional freeze-thawing they applied decreased the VC content. Burg \& Fraile ${ }^{(15)}$ showed that steaming at $200^{\circ} \mathrm{C}$ by using a superheated steam oven reduced VC in potatoes by $73 \%$. Elsewhere, exposing mashed potatoes served to hospitalised patients to a cool-chill-plated catering system resulted in a $76 \%$ loss of $\mathrm{VC}^{(27)}$. In contrast, commercial potato chips prepared from the same lot of potatoes contained a much larger amount of VC $(57 \cdot 2$ (SEM $0 \cdot 4) \mathrm{mg} / 100 \mathrm{~g})$. In good accord with the previous report, frying in oil increased $\mathrm{VC}$ content per fresh weight of potatoes by decreasing their water content from about 80 to $2 \%$ despite partial loss of VC in the process ${ }^{(16)}$. Thus, commercial potato chips, because of their substantial content of $\mathrm{VC}$ and ready availability, are a more efficient source of $\mathrm{VC}$ than home-processed potatoes.

In the present study, subjects consumed orally $282 \mathrm{~g}$ mashed potatoes and $87 \mathrm{~g}$ potato chips, each portion containing $50 \mathrm{mg}$ VC. This amount is suitable for one daily serving in a meal and snack, and almost all of this VC is absorbed in the intestine $^{(20,21)}$. In human subjects, the metabolism and utilisation of orally administered, oxidised VC are equivalent to those of reduced $\mathrm{VC}^{(22,28-31)}$. Therefore, to make an appropriate comparison, we evaluated the bioavailability of $\mathrm{VC}$ in potatoes by measuring the $\mathrm{VC}$ content in plasma and its excretion in urine. Previously, a high dose of oral VC drastically increased VC concentration in the blood ${ }^{(20,21)}$. Consistently, though, a quantity of VC intake beyond renal tubules' reabsorption capability is readily excreted into urine ${ }^{(20,21)}$. Levine et $a l^{(20,21)}$ reported that little $\mathrm{VC}$ was excreted in urine during the $24 \mathrm{~h}$ following a single oral dose of $<50 \mathrm{mg}$ 
VC, whereas that after $>100 \mathrm{mg}$ VC dramatically increased in healthy volunteers. Therefore, such a large dose of oral VC might cause difficulty in examining the bioavailability of $\mathrm{VC}$ in food. To overcome this difficulty, we set the amount of orally administered $\mathrm{VC}$ in potatoes at $50 \mathrm{mg}$, which is half the RDA $\left(100 \mathrm{mg}\right.$ ) for VC in Japan ${ }^{(32)}$. However, our highly sensitive method for the measurement of $\mathrm{VC}^{(25)}$ enabled us to detect accurately even slight changes of $\mathrm{VC}$ in plasma.

As far as we know, few reports describe the bioavailability of $\mathrm{VC}$ from food, raw or processed. In one such report, Mangels et $a l .{ }^{(33)}$ measured VC depletion-repletion during an 8 -week period and found that the bioavailability of VC from oranges, orange juice and cooked broccoli is similar to that of synthetic VC; the exception was raw broccoli, which was $20 \%$ lower. Van het Hof et al. ${ }^{(34)}$ noted that plasma VC concentrations increased after a $4 \mathrm{~d}$ diet of vegetables such as broccoli, green peas, whole-leaf spinach, and chopped spinach in accordance with their VC contents. That group also showed that chopping whole-leaf spinach did not improve the bioavailability of VC. Sánchez-Moreno et $a l .^{(35,36)}$ stated that drinking orange juice and Mediterranean vegetable soup (gazpacho) increased plasma VC concentrations in a doseresponse manner and that daily consumption for $14 \mathrm{~d}$ provided a continuously higher plasma VC concentration than that of the baseline. Also, the consumption of pulsed electric fields-processed orange juice with a long shelf-life increased plasma VC concentration to a similar extent as freshly squeezed orange juice, both in one dose and in daily doses for $14 \mathrm{~d}^{(37)}$.

Potatoes are consumed worldwide and are the major dietary staple in many countries of Europe and South America. However, this choice is less common in Japan. Interestingly, potatoes and potato chips are an important source of $\mathrm{VC}$ ( $17 \mathrm{mg} / \mathrm{d}$ in men and about $7 \mathrm{mg} / \mathrm{d}$ in women) for humans, especially those with a low plasma VC status $(<11.4 \mu \mathrm{mol} / \mathrm{l})$. Despite this acknowledgement published after a third Glasgow MONICA population survey ${ }^{(38)}$, it is surprising that there was no evidence about the bioavailability of $\mathrm{VC}$ in potatoes. Consequently, the present result in which plasma VC concentration and urinary excretion of $\mathrm{VC}$ increased during the $8 \mathrm{~h}$ period after the oral intake of mashed potatoes and potato chips is unique and suggests that VC from potatoes is readily absorbed in the intestine and transferred to the blood. Also shown was that the bioavailability of VC from potato chips is closely similar to that from mashed potatoes. Clearly, despite the processing methods of steaming/mashing and frying, VC from potatoes retains adequate bioavailability. Moreover, humans gain more VC from potato chips than from mashed potatoes when comparable proportions are eaten. However, the energy from mashed potatoes and potato chips are $351 \mathrm{~kJ}$ and $2318 \mathrm{~kJ} / 100 \mathrm{~g}$, respectively ${ }^{(2)}$. In the present study, the human subjects took $282 \mathrm{~g}$ mashed potatoes and $87 \mathrm{~g}$ potato chips, which have $990 \mathrm{~kJ}$ and $2017 \mathrm{~kJ}$ of total energy respectively. Thus, people, especially obese individuals, should hesitate to consume a large amount of potato foods.

In the present study, increased plasma VC concentrations were less at $1,1.5,2,2.5 \mathrm{~h}$ after intake of mashed potatoes and potato chips than that of $\mathrm{VC}$ in water. However, after $3 \mathrm{~h}$, which was the time of maximal $\mathrm{VC}$ level, the concentrations did not differ significantly among the three food groups. However, less VC was lost in urine after potato ingestion than from $\mathrm{VC}$ in water alone, corresponding to a slower increase in VC concentration in plasma.

Water consumption, that is, no intake of $\mathrm{VC}$ in subjects did not largely affect the increased VC concentration in plasma, the AUC for increased VC in plasma, and the urinary excretion of VC in subjects except for the slight increase of VC from 5 to $8 \mathrm{~h}$ after consumption. In fact, to our knowledge, a study examining VC concentration in plasma after water consumption has not been reported previously. Although it is uncertain as to the reason why $\mathrm{VC}$ concentration in plasma after water consumption was slightly increased, we considered that long-time fasting over $17 \mathrm{~h}$ might increase the VC concentration in plasma via the leakage of VC from cells in tissues such as liver.

Some limitations here are that mashed potatoes and potato chips are solid foods containing much starch; therefore, digestion might take longer and VC absorption in intestinal lumen could be slower compared with VC in water, which has the fastest absorption time. Our time course was set at $8 \mathrm{~h}$ after the administration of potatoes, because of ethical concerns for volunteers who underwent overnight fasting. However, to obtain fully convincing conclusions, the study should be extended until $24 \mathrm{~h}$ have elapsed, which was not done here because feeding meals to subjects might affect VC metabolism in their bodies. Another possibility is that the transport of $\mathrm{VC}$ into tissues from the blood was enhanced by some nutrient(s) of potatoes, which resulted in an apparently slower increase of VC in plasma. That is, extracellular VC is transported into the cytoplasm by the Na dependent VC transporters 1 and 2 in a reduced form and by the GLUT1, GLUT3 and GLUT4 in an oxidised form ${ }^{(17,18,39)}$. As almost all $\mathrm{VC}$ in the blood exists in a reduced form ${ }^{(20)}$, SVCT1 and SVCT2 are mainly responsible for taking up VC from the blood and into the cytoplasm of multiple tissues. SVCT1, which is expressed in such tissues as the intestine, liver, lung, kidney and skin, is involved in whole-body homeostasis ${ }^{(17)}$. SVCT2, which is expressed in the brain, eye, liver, kidney, intestine, adrenal gland, bone and skeletal muscle, is a high-affinity VC transporter to maintain high VC concentrations in tissues ${ }^{(17)}$. As recently reported, SVCT2-mediated VC uptake is quickly enhanced by the translocation of cytoplasmic SVCT2 to plasma membranes from various types of stimulation ${ }^{(40)}$. Since the regulation of SVCT2-mediated VC uptake is not fully understood, the present results might imply the existence of novel SVCT2-activating nutrient(s) in potatoes.

We have performed this experiment employing only male subjects. As shown in previous papers ${ }^{(20,21)}$, VC metabolism in human subjects is not largely different between males and females. Thus, it is considered that the present data about the bioavailability of $\mathrm{VC}$ in mashed potatoes and potato chips could be applicable to females.

In conclusion, the bioavailability of $\mathrm{VC}$ in mashed potatoes and potato chips was documented in the present oral, singledose study. The consumption of mashed potatoes and potato 
chips increased the VC concentration in plasma, and less VC tended to be excreted in urine than was consumed. These results explicitly confirm the nutritional value of mashed potatoes and potato chips as a dietary VC source as demonstrated here in a cohort of Japanese males.

\section{Acknowledgements}

We thank Ms P. Minick for the excellent English editorial assistance. There was no funding for the present study. There are no conflicts of interest. The authors' contributions are as follows: Y. K., C. H., K. I., S. H., H. M., N. M., H. K. and A. I. designed the research; Y. K., C. H. and M. I. conducted the research; Y. K. and C. H. analysed the data; Y. K. wrote the paper and had primary responsibility for the final content. All authors read and approved the final manuscript.

\section{References}

1. Camire ME, Kubow S \& Donnelly DJ (2009) Potatoes and human health. Crit Rev Food Sci Nutr 49, 823-840.

2. The Council for Science and Technology; Ministry of Education, Culture, Sports, Science and Technology, Japan (2010) Standard Tables of Food Composition in Japan. Tokyo, Japan: National Printing Bureau.

3. Linster CL \& Van Schaftingen E (2007) Vitamin C. Biosynthesis, recycling and degradation in mammals. FEBS J 274, 1-22.

4. Joshipura KJ, Hu FB, Manson JE, et al. (2001) The effect of fruit and vegetable intake on risk for coronary heart disease. Ann Intern Med 134, 1106-1114.

5. Kurl S, Tuomainen TP, Laukkanen JA, et al. (2002) Plasma vitamin $\mathrm{C}$ modifies the association between hypertension and risk of stroke. Stroke 33, 1568-1573.

6. Yokoyama T, Date C, Kokubo Y, et al. (2000) Serum vitamin C concentration was inversely associated with subsequent 20 -year incidence of stroke in a Japanese rural community. The Shibata study. Stroke 31, 2287-2294.

7. Myint PK, Luben RN, Welch AA, et al. (2008) Plasma vitamin C concentrations predict risk of incident stroke over $10 \mathrm{y}$ in 20649 participants of the European Prospective Investigation into Cancer Norfolk prospective population study. Am J Clin Nutr 87, 64-69.

8. Joshipura KJ, Ascherio A, Manson JE, et al. (1999) Fruit and vegetable intake in relation to risk of ischemic stroke. JAMA 282, 1233-1239.

9. Jacques PF, Taylor A, Hankinson SE, et al. (1997) Long-term vitamin $C$ supplement use and prevalence of early agerelated lens opacities. Am J Clin Nutr 66, 911-916.

10. Yoshida M, Takashima Y, Inoue M, et al. (2007) Prospective study showing that dietary vitamin $\mathrm{C}$ reduced the risk of agerelated cataracts in a middle-aged Japanese population. EurJ Nutr 46, 118-124.

11. Harding AH, Wareham NJ, Bingham SA, et al. (2008) Plasma vitamin $\mathrm{C}$ level, fruit and vegetable consumption, and the risk of new-onset type 2 diabetes mellitus: the European prospective investigation of cancer-Norfolk prospective study. Arch Intern Med 168, 1493-1499.

12. Afkhami-Ardekani M \& Shojaoddiny-Ardekani A (2007) Effect of vitamin $\mathrm{C}$ on blood glucose, serum lipids \& serum insulin in type 2 diabetes patients. Indian J Med Res 126, $471-474$.
13. Sasazuki S, Sasaki S, Tsubono Y, et al. (2006) Effect of vitamin $\mathrm{C}$ on common cold: randomized controlled trial. Eur J Clin Nutr 60, 9-17.

14. Han JS, Kozukue N, Young KS, et al. (2004) Distribution of ascorbic acid in potato tubers and in home-processed and commercial potato foods. J Agric Food Chem 52, 6516-6521.

15. Burg P \& Fraile P (1995) Vitamin C destruction during the cooking of a potato dish. Lebensm-Wiss u Technol $\mathbf{2 8}$, 506-514.

16. Miyoshi T, Ishihara K, Nakamura K, et al. (2006) Antioxidative compounds in potato chips. JSCS 39, 277-282.

17. Wilson JX (2005) Regulation of vitamin C transport. Annu Rev Nutr 25, 105-125.

18. May JM, Qu ZC \& Qiao H (2009) Transfer of ascorbic acid across the vascular endothelium: mechanism and selfregulation. Am J Physiol Cell Physiol 297, C169-C178.

19. Reidling JC, Subramanian VS, Dahhan T, et al. (2008) Mechanisms and regulation of vitamin $C$ uptake: studies of the hSVCT systems in human liver epithelial cells. Am J Physiol Gastrointest Liver Physiol 295, G1217-G1227.

20. Levine M, Conry-Cantilena C, Wang Y, et al. (1996) Vitamin C pharmacokinetics in healthy volunteers: evidence for a recommended dietary allowance. Proc Natl Acad Sci U S A 93, 3704-3709.

21. Levine M, Wang Y, Padayatty SJ, et al. (2001) A new recommended dietary allowance of vitamin $\mathrm{C}$ for healthy young women. Proc Natl Acad Sci U S A 98, 9842-9846.

22. Higasa S, Tsujimura M, Hiraoka M, et al. (2007) Polymorphism of glutathione S-transferase P1 gene affects human vitamin C metabolism. Biochem Biophys Res Commun 364 , 708-713.

23. Bates CJ, Jones KS \& Bluck LJ (2004) Stable isotope-labelled vitamin $\mathrm{C}$ as a probe for vitamin $\mathrm{C}$ absorption by human subjects. Br J Nutr 91, 699-705.

24. Johnston CS \& Luo B (1994) Comparison of the absorption and excretion of three commercially available sources of vitamin C. J Am Diet Assoc 94, 779-781.

25. Sato Y, Uchiki T, Iwama M, et al. (2010) Determination of dehydroascorbic acid in mouse tissues and plasma by using tris(2-carboxyethyl)phosphine hydrochloride as reductant in metaphosphoric acid/ethylenediaminetetraacetic acid solution. Biol Pharm Bull 33, 364-369.

26. Fabiny DL \& Ertingshausen G (1971) Automated reactionrate method for determination of serum creatinine with the CentrifiChem. Clin Chem 17, 696-700.

27. McErlain L, Marson H, Ainsworth P, et al. (2001) Ascorbic acid loss in vegetables: adequacy of a hospital cook-chill system. Int J Food Sci Nutr 52, 205-211.

28. Tsujimura M, Higasa S, Nakayama K, et al. (2008) Vitamin C activity of dehydroascorbic acid in humans - association between changes in the blood vitamin $\mathrm{C}$ concentration or urinary excretion after oral loading. $J$ Nutr Sci Vitaminol (Tokyo) 54, 315-320.

29. Tsujimura M \& Higasa S (2007) Vitamin C activity of L-dehydroascorbic acid in human. Time-dependent vitamin $\mathrm{C}$ concentration in blood and urinary excretion after the oral load. Vitamins 81, 489-496.

30. Tsujimura M, Watanabe S, Michinaka K, et al. (1972) Metabolism of ascorbic acid and dehydroascorbic acid in man. Vitamins 45, 136-147.

31. Tsujimura M, Higasa S, Aono K, et al. (2006) Vitamin C activity of L-dehydroascorbic acid in human. Timedependent vitamin $\mathrm{C}$ urinary excretion after the oral load. Vitamins 70, 241-248. 
32. Ministry of Health, Labour, and Welfare, Japan (2005) Dietary Reference Intakes for Japanese, 2005. Tokyo, Japan: Daiichi Shuppan Publishing Co, Ltd.

33. Mangels AR, Block G, Frey CM, et al. (1993) The bioavailability to humans of ascorbic acid from oranges, orange juice and cooked broccoli is similar to that of synthetic ascorbic acid. J Nutr 123, 1054-1061.

34. van het Hof KH, Tijburg LB, Pietrzik K, et al. (1999) Influence of feeding different vegetables on plasma levels of carotenoids, folate and vitamin C. Effect of disruption of the vegetable matrix. Br J Nutr 82, 203-212.

35. Sanchez-Moreno C, Cano MP, de Ancos B, et al. (2003) Effect of orange juice intake on vitamin $\mathrm{C}$ concentrations and biomarkers of antioxidant status in humans. Am J Clin Nutr $\mathbf{7 8}$, 454-460.

36. Sanchez-Moreno C, Cano MP, de Ancos B, et al. (2006) Mediterranean vegetable soup consumption increases plasma vitamin $\mathrm{C}$ and decreases $\mathrm{F} 2$-isoprostanes, prostaglandin E2 and monocyte chemotactic protein-1 in healthy humans. J Nutr Biochem 17, 183-189.

37. Sanchez-Moreno C, Cano MP, de Ancos B, et al. (2004) Pulsed electric fields-processed orange juice consumption increases plasma vitamin $\mathrm{C}$ and decreases F2-isoprostanes in healthy humans. J Nutr Biochem 15, 601-607.

38. Wrieden WL, Hannah MK, Bolton-Smith C, et al. (2000) Plasma vitamin $\mathrm{C}$ and food choice in the third Glasgow MONICA population survey. I Epidemiol Community Health 54, 355-360.

39. Corti A, Casini AF \& Pompella A (2010) Cellular pathways for transport and efflux of ascorbate and dehydroascorbate. Arch Biochem Biophys 500, 107-115.

40. Wu X, Zeng LH, Taniguchi T, et al. (2007) Activation of PKA and phosphorylation of sodium-dependent vitamin $\mathrm{C}$ transporter 2 by prostaglandin E2 promote osteoblast-like differentiation in MC3T3-E1 cells. Cell Death Differ 14, $1792-1801$ 